Fixed Point Theory, 22(2021), No. 1, 377-390

DOI: $10.24193 /$ fpt-ro.2021.1.26

http://www.math.ubbcluj.ro/ nodeacj/sfptcj.html

\title{
APPROXIMATING COMMON FIXED POINTS OF ASYMPTOTICALLY NONEXPANSIVE COSINE FAMILIES IN HILBERT SPACES BY ALGORITHMS WITH ERROR TERMS
}

\author{
JIAN-ZHONG XIAO* AND YUE ZHU** \\ *School of Mathematics and Statistics, \\ Nanjing University of Information Science and Technology, \\ Nanjing 210044, PR China \\ E-mail: xiaojz@nuist.edu.cn \\ **School of Computer and Software, \\ Nanjing University of Information Science and Technology, \\ Nanjing 210044, PR China \\ E-mail: zhuynuist@163.com
}

\begin{abstract}
In this paper the Mann type iterative scheme with error term to approximate a common fixed point of one-parameter asymptotically nonexpansive cosine family is investigated in Hilbert spaces. By using the theory of cosine families, some strong convergence theorems of the sequences generated by these schemes are established on closed convex subsets and compact convex subsets, respectively. As special cases, strong convergence results for nonexpansive cosine families are also obtained.

Key Words and Phrases: Asymptotically nonexpansive cosine family, common fixed point, Mann type iterative scheme with error term, strong convergence.
\end{abstract}

2020 Mathematics Subject Classification: 47H10, 47D09, 65J05.

Acknowledgment. This work is supported by the Natural Science Foundation of China (Grant No. 11571176).

\section{REFERENCES}

[1] S.A. Ahmed, A.A. El-Sayed, A.K.A. Bukhari, V.Ć. Rajić, Fixed points by some iterative algorithms in Banach and Hilbert spaces with some applications, J. Comput. Anal. Appl., 20(2016), 707-717.

[2] A. Aleyner, Y. Censor, Best approximation to common fixed points of a semigroup of nonexpansive operators, J. Nonlinear Convex Anal., 6(2005), 137-151.

[3] J. Borwein, S. Reich, I. Shafrir, Krasnoselskii-Mann iterations in normed spaces, Canad. Math. Bull., 35(1992), 21-28.

[4] R.E. Bruck, T. Kuczumow, S. Reich, Convergence of iterates of asymptotically nonexpansive mappings in Banach spaces with the uniform Opial property, Colloquium Math., 65(1993), 169-179.

[5] S.S. Chang, K.K. Tan, H.W.J. Lee, C. K. Chan, On the convergence of implicit iteration process with error for a finite family of asymptotically nonexpansive mappings, J. Math. Anal. Appl., 313(2006), 273-283. 
[6] Y.J. Cho, X.L. Qin, Convergence of a general iterative method for nonexpansive mappings in Hilbert spaces, J. Comput. Appl. Math., 228(2009), 458-65.

[7] F. Cianciaruso, G. Marino, L. Muglia, Iterative methods for equilibrium and fixed point problems for nonexpansive semigroups in Hilbert spaces, J. Optim. Theory Appl., 146(2010), 491-509.

[8] W.Q. Deng, Strong convergence of Mann's type iteration method for an infinite family of generalized asymptotically nonexpansive nonself mappings in Hilbert spaces, Optim. Letters, 8(2014), 533-42.

[9] H. Fukhar-ud-din, A.R. Khan, Convergence of implicit iterates with errors for mappings with unbounded domain in Banach spaces, Inter. J. Math. Math. Sci., 10(2005), 1643-1653.

[10] K. Goebel, W.A. Kirk, A fixed point theorem for asymptotically nonexpansive mappings, Proc. Amer. Math. Soc., 35(1972), 171-174.

[11] Z. Huang, Mann and Ishikawa iterations with errors for asymptotically nonexpansive mappings, Comput. Math. Appl., 37(1999), 1-7.

[12] N. Hussain, G. Marino, L. Muglia, A.A.N. Abdou, On the strong convergence of a general-type Krasnosel'skii Mann's algorithm depending on the coefficients, J. Fixed Point Theory Appl., 18(2016), 1-25.

[13] N. Hussain, G. Marino, L. Muglia, B.A.S. Alamr, On some Mann's type iterative algorithms, Fixed Point Theory Appl., 17(2015), 1-16.

[14] U. Kamraksa, R. Wangkeere, Generalized equilibrium problems and fixed point problems for nonexpansive semigroups in Hilbert spaces, J. Global Optim., 51(2011), 689-714.

[15] U. Kohlenbach, A. Koutsoukou-Argyraki, Effective asymptotic regularity for one-parameter nonexpansive semigroups, J. Math. Anal. Appl., 433(2016), 1883-1903.

[16] G. Marino, H.K. Xu, Weak and strong convergence theorems for strict pseudo-contractions in Hilbert spaces, J. Math. Anal. Appl., 329(2007), 336-346.

[17] H. Piri, P. Kumam, Strong convergence theorems for fixed points of asymptotically nonexpansive semigroups in Banach spaces, Fixed Point Theory Appl., 225(2014), 1-15.

[18] S. Reich, Weak convergence theorems for nonexpansive mappings in Banach spaces, J. Math. Anal. Appl., 67(1979), 274-276.

[19] J. Schu, Weak and Strong convergence to fixed points of asymptotically nonexpansive mappings, Bull. Austral. Math. Soc., 43(1991), 153-159.

[20] J. Schu, Approximation of fixed points of asymptotically nonexpansive mappings, Proc. Amer. Math. Soc., 112(1991), 143-151.

[21] Y. Shehu, An iterative method for nonexpansive semigroups, variational inclusions and generalized equilibrium problems, Math. Comput. Modelling, 55(2012), 1301-1314.

[22] T. Suzuki, On strong convergence to common fixed points of nonexpansive semigroups in Hilbert space, Proc. Amer. Math. Soc., 131(2002), 2133-2136.

[23] T. Suzuki, Strong convergence of Krasnoselskii and Mann's type sequences for one-parameter nonexpansive semigroups without Bochner integrals, J. Math. Anal. Appl., 305(2005), 227-239.

[24] T. Suzuki, Browder's type convergence theorems for one parameter semi-groups of nonexpansive mappings in Banach spaces, Israel J. Math., 157(2007), 239-257.

[25] K.K. Tan, H.K. Xu, Approximating fixed points of nonexpansive mappings by the Ishikawa iteration process, J. Math. Anal. Appl., 178(1993), 301-308.

[26] K.K. Tan, X.H. Xu, Fixed point iteration processes for asymptotically nonexpansive mappings, Proc. Amer. Math. Soc., 122(1994), 733-739.

[27] N.T.T. Thuy, Hybrid Mann-Halpern iteration methods for finding fixed points involving asymptotically nonexpansive mappings and semigroups, Vietnam. J. Math., 42(2014), 219-232.

[28] J.-Z. Xiao, J. Sun, X. Huang, Approximating common fixed points of asymptotically quasinonexpansive mappings by a k+1-step iterative scheme with error terms, J. Comput. Appl. Math., 233(2010), 2062-2070.

[29] J.Z. Xiao, J. Yan, X.H. Zhu, Explicit, implicit and viscosity iterations for nonexpansive cosine families in Hilbert spaces, Acta Math. Sci. (Ser. A), 34(2014), 1518-1531.

[30] B.L. Xu, M.A. Noor, Fixed-point iterations for asymptotically nonexpansive mappings in Banach spaces, J. Math. Anal. Appl., 267(2002), 444-453. 
[31] A.J. Zaslavski, Approximate Solutions of Common Fixed Point Problems, Springer Optimization and Its Applications, Springer, 2016.

[32] A.J. Zaslavski, Algorithms for Solving Common Fixed Point Problems, Springer Optimization and Its Applications, Springer, 2018.

[33] X.H. Zhu, J.Z. Xiao, Minimum selections and fixed points of set-valued operators in Banach spaces with some uniform convexity, Appl. Math. Comput., 217(2011), 6004-6010.

Received: January 17, 2019; Accepted: June 10, 2019. 